\title{
Estimation of the Fracture Toughness Threshold of a Ferritic Steel at the Lower Ductile to Brittle Transition Region
}

\author{
Carlos Berejnoi $^{a *, \text { Santiago Vacca }}{ }^{b}$, Claudia Galarza ${ }^{a}$, Juan Elías Perez Ipiña ${ }^{c, d}$ \\ ${ }^{a}$ Facultad de Ingeniería, Consejo de Investigación de la Universidad Nacional de Salta-CIUNSa, \\ Universidad Nacional de Salta, Avda. Bolivia 5500, Salta, Argentina \\ ${ }^{b}$ Facultad Ingeniería, Instituto de Ensayo de Materiales, Universidad de la República, Montevideo, \\ Uruguay \\ c Grupo Mecánica de Fractura, Universidad Nacional del Comahue, Neuquén, Argentina \\ ${ }^{d}$ Consejo Nacional de Investigaciones Científicas y Técnicas - CONICET, Neuquén, Argentina
}

Received: August 31, 2015; Revised: March 23, 2016; Accepted: July 28, 2016

\begin{abstract}
The ADN420 ferritic steel (A615 steel Grade 60 [420]), used as reinforcing bars (rebar) in concrete, shows the so called ductile to brittle transition. Room temperature is located on the lower third region of the transition zone. In this work, the fracture toughness of this steel working at room temperature was studied statistically. For such a purpose, 125 compact test specimens were machined from commercial bars and tested at room temperature to determine the $\mathrm{Jc}$ and $\mathrm{K}_{\mathrm{Jc}}$ critical fracture toughness values. Several continuous probability functions with threshold parameter were adjusted to the $\mathrm{J}$ and $\mathrm{K}$ datasets.
\end{abstract}

Keywords: ferritic steels, fracture toughness, scatter, threshold, weakest link

\section{Introduction}

The fracture toughness of materials working at the ductile to brittle transition usually shows considerable scatter ${ }^{1-8}$. It is believed that the relative position of the crack tip related to microstructural heterogeneities causes the scatter, this theory is known as the weakest link theory ${ }^{2-4}$. In this case, the resulting statistical distribution characterizes the fracture toughness of the tested specimens. From a fracture mechanics point of view, the material will be as reliable as that point with the worst possible microstructural heterogeneity relative to the crack tip. Thus, the fracture toughness corresponding to this worst situation, which can be characterized by a threshold parameter of the statistical distribution, becomes a technologically interesting parameter. Further, it is considered as thickness independent, since a thicker test piece will only increase the chances of having the most unfavorable microstructural heterogeneity relative to the crack tip; affecting scatter, but not the threshold value, being this a material property. Validating this theory presents the difficulty that the sample sizes required to statistically characterize a material for different temperatures and thicknesses makes it economically impractical.

Experimental data may be fitted by means of different statistical functions. If one statistical distribution function is known to be correct for certain physical or characteristic property, then it is possible to estimate all the parameters for such a distribution. In this way, the minimum toughness of a material could be estimated as a threshold parameter or the value for a probability failure level of the statistical distribution.

For the fracture toughness characterization of ferritic steels in the ductile to brittle transition zone, it is quite common to calculate the J integral and then convert the results to the stress intensity factor K (Eq. (1)).

$$
K_{J_{C}}=\sqrt{\frac{E J_{C}}{\left(1-v^{2}\right)}}
$$

$v$ is the Poisson coefficient (0.3) and E the Young modulus (210 GPa).

The results are adjusted mostly with a two parameter Weibull distribution (2P-W) $)^{1,3,9-13}$, Eq. (2), or with a three parameter WeibullI distribution (3P-W) $)^{2,4,14,15}$, Eq. (3), both in terms of $\mathrm{J}_{\mathrm{C}}$ or $\mathrm{K}_{\mathrm{Jc}}$

$$
\begin{gathered}
P=1-\exp \left[-\left(\frac{J_{C}}{J_{0}}\right)^{b_{J}}\right](2) \\
P=1-\exp \left[-\left(\frac{K_{J_{c}}}{K_{0}}\right)^{b_{K}}\right] \\
P=1-\exp \left[-\left(-\frac{J_{C}-J_{\min }}{J_{0}-J_{\min }}\right)^{b /}\right](3) \\
P=1-\exp \left[-\left(\frac{K_{J_{c}}-K_{\min }}{K_{0}-K_{\min }}\right)^{b_{K}}\right]
\end{gathered}
$$

The scale parameter $\left(J_{0}\right.$ or $\left.K_{0}\right)$ corresponds to the fracture toughness value that gives a probability failure of $63 \%$. The shape parameter $\left(b_{J}\right.$ or $\left.b_{K}\right)$ is also known as Weibull slope. For a 3P-W distribution, the threshold parameter is incorporated $\left(J_{\min }\right.$ or $\left.K_{\min }\right)$. 
The standard ASTM E1921-15 ${ }^{8}$ indicates the statistical treatment of $\mathrm{K}$ values derived from $\mathrm{J}$ results for 1 " compact specimen (1T-CT), with the use of a 3P-W distribution, considering two of the parameters as fixed (Eq. (4)).

$$
P=1-\exp \left[-\left(\frac{K_{J_{c}}-20}{K_{0}-20}\right)^{4}\right]
$$

Other statistical functions may be used, such as the lognormal and some exponential based distributions ${ }^{16}$.

The ADN 420 steel, equivalent to the A615 steel Grade $60^{17}$, is used as reinforcing bars for concrete. On the material designation, "ADN" stands for "naturally hardened steel" in Spanish and " 420 " for minimum yield strength of $420 \mathrm{MPa}$. For this steel, room temperature corresponds to the lower third of the ductile-to-brittle transition region.

A large set, from a fracture toughness tests point of view, of AND 420 specimens was tested in this work in order to assure it was representative of the population. Threshold parameters were estimated using different statistical distributions and then compared.

\section{Material and methods}

\subsection{Fracture toughness tests}

The critical fracture toughness $\left(\mathrm{J}_{\mathrm{C}}\right)$ of the ADN 420 steel was determined by testing compact specimens $(\mathrm{C}(\mathrm{T}))$ at $20{ }^{\circ} \mathrm{C}$, according to the ASTM 1820-13e1 standard ${ }^{18}$. This material is produced as cylindrical bars by continuous casting, and then hot rolled to different final diameters (38 $\mathrm{mm}$ bars were used in this work).

A total of $126 \mathrm{C}(\mathrm{T})$ specimens were machined to a width of $25 \mathrm{~mm}$ and a thickness of $12.5 \mathrm{~mm}$ with the crack in the R-L orientation according to ASTM E1823-13 ${ }^{19}$ (Figure 1). The specimens where pre-cracked in a displacement controlled fatigue test machine.

The specimens where tested in a $100 \mathrm{KN}$ Amsler screw testing machine. Tests were quasi-static, loading rate was 1 MPa.m ${ }^{1 / 2}$. Force (P) was measured with a $20 \mathrm{kN}$ load cell and displacements ( $\mathrm{v}$ ) with a clip-gage mounted at the knife edges of the specimens, which were collinear to the load line. Measurements were digitally recorded to a PC. Tested specimens were cooled to $-20^{\circ} \mathrm{C}$ and then fractured in the Amsler testing machine.

Jc values were calculated according to ASTM E1820$13 \mathrm{e} 1^{18}$ from the $\mathrm{P}$ vs. $\mathrm{v}$ records and specimen dimensions, then they were converted into $\mathrm{K}_{\mathrm{Jc}}$ values by means of Eq. (1).

\subsection{Statistical Analysis}

Two datasets were obtained with the procedure described above, one for Jc and one for $\mathrm{K}_{\mathrm{Jc}}$. Several continuous non-

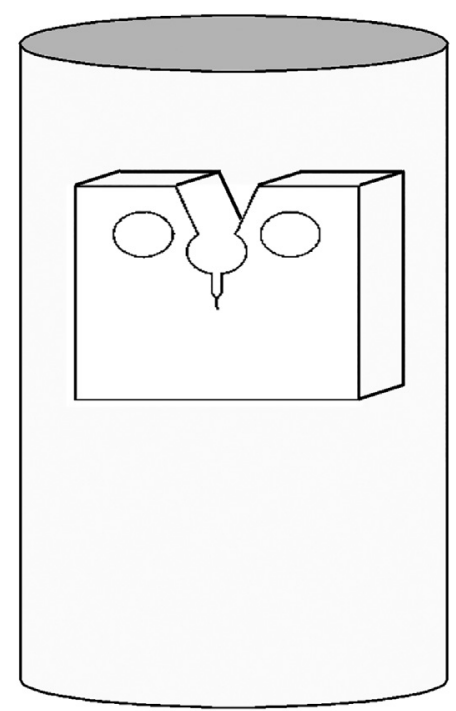

Figure 1: Specimen extraction scheme.

negative distributions, most of them with a threshold parameter, were adjusted to both datasets using Easyfit Software ${ }^{20}$ :

- Functions that includes exponential: Chi-Squared (2P), Erlang (3P), Exponential (2P), Frechet (3P), Gamma (3P), Gen. Gamma (4P), Inv. Gaussian (3P), Levy (2P), Lognormal (3P), Pearson 5 (3P), Rayleigh (2P), Weibull (3P).

- $\quad$ Functions not including exponencial: Burr (4P), Dagum (4P), Fatigue Life (3P), Log-Logistic (3P), Pareto, Pearson 6 (4P).

A number followed by the letter $\mathrm{P}$ (in parentheses) indicates the number of parameters used in each distribution, in cases where different number of parameters could be used.

For instance, Weibull (3P) responds to Eq. (3), while Eq. (2) would be used for Weibull (2P).

According to Wallin ${ }^{16}$, exponential distributions (such as Weibull, Gumbel and Log-Normal) describe fracture toughness results better than the Normal distribution. In this work, the Gumbel function was not included because it has not a threshold parameter; it is an unbounded distribution, like the Normal one, with a range of (-infinity, infinity).

\section{Results and Discussion}

From the 126 specimens machined, only 117 tests resulted geometrically valid.

Room temperature corresponds to the lower third of the ductile-to-brittle transition region for the studied material. This was verified by the fact that all the specimens presented brittle fracture with enough plastic deformation to have exceeded the allowed limits for the application of the linear elastic fracture mechanics methodology, and they did not present stable crack growth prior the cleavage. 
The obtained $\mathrm{Jc}$ and $\mathrm{K}_{\mathrm{Jc}}$ values are presented in Table 1 . The minimum and maximum measured Jc values were 12.55 and $43.63 \mathrm{~N} / \mathrm{mm}$ respectively; and their equivalent $\mathrm{K}_{\mathrm{Jc}}$ were 53.43 and $99.63 \mathrm{MPam}^{1 / 2}$ respectively. Because the tests were performed in the lower third of the transition region, all 117 specimens failed by cleavage without previous stable crack growth giving valid results $\left(\mathrm{J}_{\text {limit }}=175 \mathrm{~N} / \mathrm{mm}\right.$; $\left.\mathrm{K}_{\mathrm{Jc}(\text { limit) }}=200.96 \mathrm{MPa} \cdot \mathrm{m}^{0.5}\right)$. Figure 2 and Figure 3 show the histograms of the datasets for Jc, while the corresponding histograms for $\mathrm{K}_{\mathrm{Jc}}$ are shown in Figure 4 and Figure 5. The continuous curves that result from multiplying the probability density functions by the intervals width are also shown in these figures. The discrimination in good or bad fitting was supported by the Anderson-Darling test (also performed with Easyfit Software $\left.{ }^{20}\right)$.

Dagum (4P) does not adjust the datasets at all, being impossible to present the distribution in the scale of Figures 2 to 5 .
The threshold parameters for the adjusted distributions are shown in Figure 6 and Figure 7, for the $\mathrm{Jc}$ and $\mathrm{K}_{\mathrm{Jc}}$ datasets respectively. In the figures, the distributions are ordered from the worst fitting (left) to the best adjustment (right), according to how close is the estimated threshold parameter to the experimental minimum. Also, the values $\mathrm{J}_{\min }=11 \mathrm{~N} /$ $\mathrm{mm}$ and $\mathrm{K}_{\min }=50 \mathrm{MPa} \cdot \mathrm{m}^{1 / 2}$ are included in the figures as horizontal lines and they were used as acceptable values for threshold estimation. Figure 7 also shows the threshold imposed in ASTM E1921-15, $\mathrm{K}_{\min }=20 \mathrm{MPa} \cdot \mathrm{m}^{1 / 2}$.

The exponential type Frechet (3p) distribution is not included in Figure 6 and Figure 7 because the threshold parameter estimated for this sample resulted negative, around of $-10^{8}$.

According to Figure 6 and Figure 7, Rayleigh (2P), Weibull (3P), Exponencial (2P), Pareto and Levy (2P) are the distributions that present thresholds nearer to the ninimum experimental. Exponencial (2P), Levy (2P) and Pareto do not adjust the

Table 1: Datasets for Jc and KJc valid according to the ASTM 1820-13e1 standard.

\begin{tabular}{|c|c|c|c|c|c|c|c|}
\hline \multicolumn{4}{|c|}{$\mathrm{Jc}[\mathrm{N} / \mathrm{mm}]$} & \multicolumn{4}{|c|}{ KJc $\left[\mathrm{MPa} \cdot \mathrm{m}^{1} / 2\right]$} \\
\hline 17.08 & 20.00 & 18.79 & 37.40 & 62.78 & 67.94 & 65.85 & 92.90 \\
\hline 20.84 & 24.26 & 31.71 & 18.93 & 69.35 & 74.82 & 85.54 & 66.09 \\
\hline 17.21 & 15.26 & 22.07 & 39.56 & 63.02 & 59.34 & 71.37 & 95.55 \\
\hline 29.62 & 24.41 & 22.73 & 16.97 & 82.68 & 75.05 & 72.43 & 62.58 \\
\hline 28.20 & 13.04 & 23.88 & 26.65 & 80.67 & 54.86 & 74.23 & 78.42 \\
\hline 30.32 & 18.30 & 23.07 & 14.41 & 83.65 & 64.99 & 72.96 & 57.67 \\
\hline 21.42 & 32.42 & 16.27 & 33.83 & 70.31 & 86.50 & 61.27 & 88.36 \\
\hline 16.83 & 20.91 & 24.93 & 22.79 & 62.32 & 69.46 & 75.85 & 72.52 \\
\hline 33.01 & 19.69 & 18.97 & 21.41 & 87.28 & 67.41 & 66.16 & 70.29 \\
\hline 14.95 & 15.23 & 21.12 & 28.36 & 58.74 & 59.28 & 69.81 & 80.90 \\
\hline 29.76 & 17.02 & 27.17 & 22.87 & 82.87 & 62.67 & 79.18 & 72.65 \\
\hline 17.13 & 20.71 & 22.29 & 29.01 & 62.87 & 69.13 & 71.72 & 81.82 \\
\hline 24.03 & 16.72 & 20.64 & 27.48 & 74.47 & 62.12 & 69.02 & 79.63 \\
\hline 32.49 & 29.55 & 21.51 & 25.33 & 86.59 & 82.58 & 70.45 & 76.46 \\
\hline 17.79 & 22.17 & 23.22 & 22.33 & 64.07 & 71.53 & 73.20 & 71.78 \\
\hline 22.86 & 18.09 & 22.38 & 26.28 & 72.63 & 64.61 & 71.87 & 77.88 \\
\hline 22.00 & 43.63 & 28.06 & 17.87 & 71.25 & 100.34 & 80.47 & 64.22 \\
\hline 21.65 & 18.53 & 21.70 & 21.81 & 70.68 & 65.39 & 70.77 & 70.94 \\
\hline 16.46 & 25.04 & 19.46 & 23.67 & 61.63 & 76.02 & 67.01 & 73.91 \\
\hline 21.34 & 23.38 & 20.42 & 16.62 & 70.18 & 73.45 & 68.65 & 61.93 \\
\hline 23.16 & 20.49 & 26.31 & 21.56 & 73.11 & 68.76 & 77.92 & 70.54 \\
\hline 26.03 & 30.52 & 19.72 & 27.26 & 77.50 & 83.92 & 67.46 & 79.31 \\
\hline 23.21 & 33.52 & 22.33 & 18.44 & 73.19 & 87.95 & 71.78 & 65.23 \\
\hline 27.61 & 22.64 & 21.10 & 22.18 & 79.82 & 72.28 & 69.78 & 71.54 \\
\hline 15.88 & 17.76 & 23.94 & 18.27 & 60.54 & 64.02 & 74.33 & 64.93 \\
\hline 26.20 & 25.95 & 22.10 & 18.42 & 77.76 & 77.39 & 71.41 & 65.20 \\
\hline 31.11 & 15.78 & 43.50 & 20.95 & 84.73 & 60.35 & 100.19 & 69.53 \\
\hline 19.62 & 12.55 & 22.62 & & 67.29 & 53.82 & 72.25 & \\
\hline 24.14 & 13.28 & 30.94 & & 74.64 & 55.36 & 84.50 & \\
\hline 23.54 & 20.17 & 15.80 & & 73.70 & 68.22 & 60.38 & \\
\hline
\end{tabular}




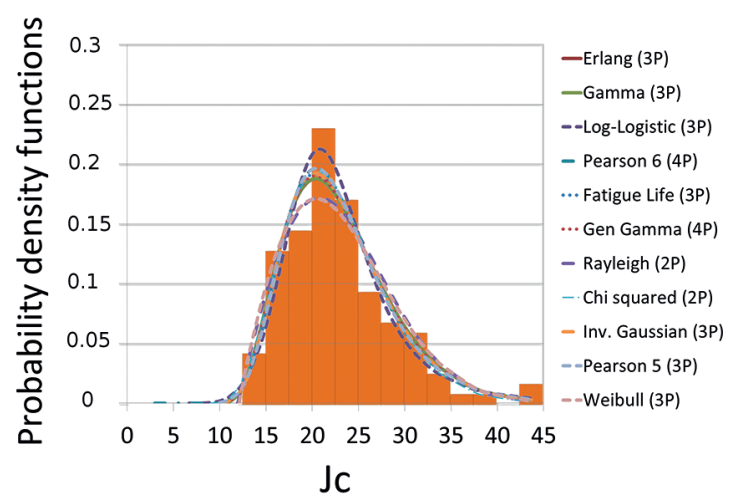

Figure 2: Histogram and scaled probability density functions. Good fittings for Jc results.

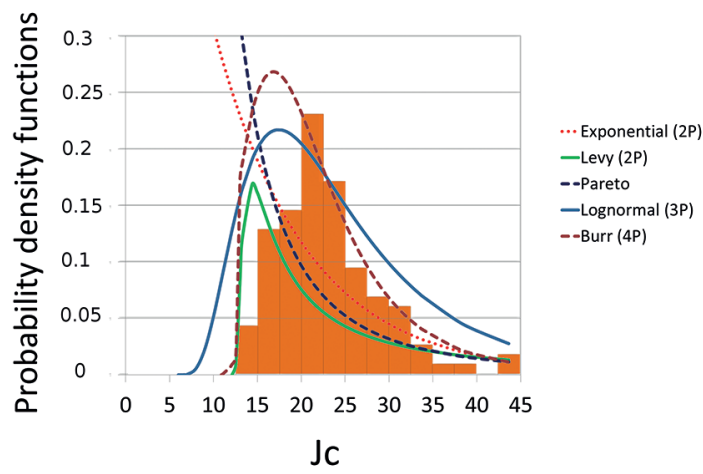

Figure 3: Histogram and scaled probability density functions. Bad fittings for Jc results.

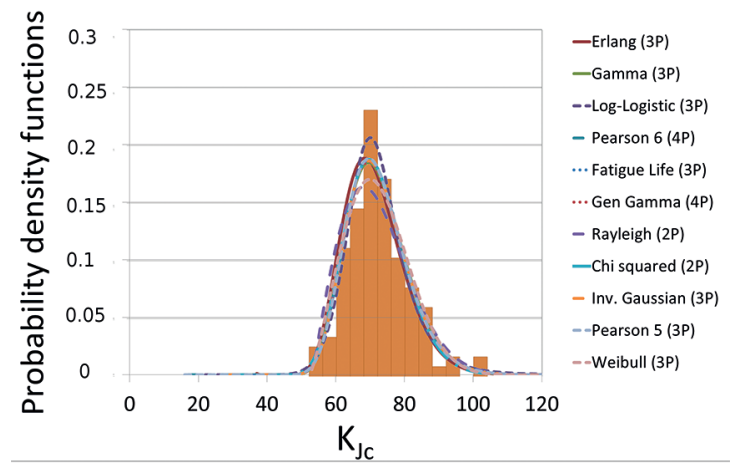

Figure 4: Histogram and scaled probability density functions. Good fittings for $\mathrm{K}_{\mathrm{Jc}}$ results.

histograms neither in Jc nor in $\mathrm{K}_{\mathrm{Jc}}$ (Figure 3 and Figure 5). It is also seen that the $3 \mathrm{PW}$ distribution adjusts fairly to both Jc and $\mathrm{K}_{\mathrm{Jc}}$ datasets while giving a high threshold parameter, lower than the minimum experimental and close to it.

Also, Pareto has not a true threshold parameter. It is a non negative function, that has an scale parameter $(\beta)$, which defines the range of the function: $(\beta, \infty)$. In all of the analyzed cases, this parameter resulted equal to the experimental minimum.

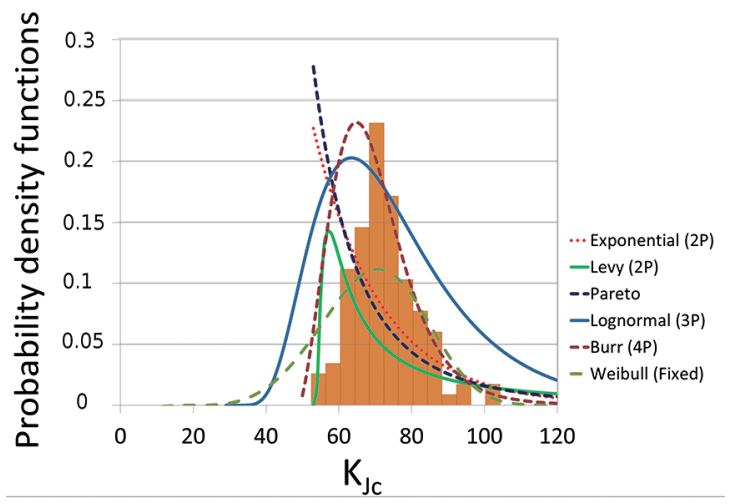

Figure 5: Histogram and scaled probability density functions. Bad fittings for $\mathrm{K}_{\mathrm{Jc}}$ results.

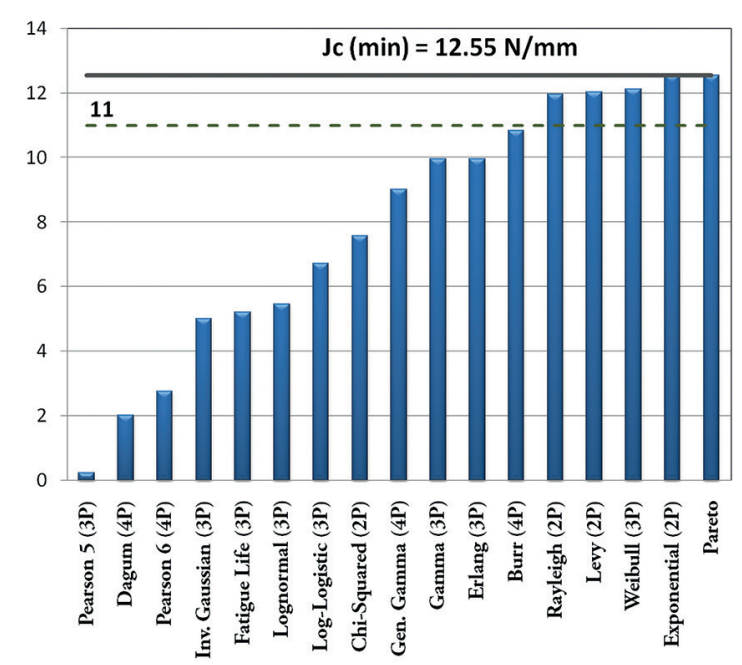

Figure 6: Threshold parameters for the adjusted distributions to the Jc dataset.

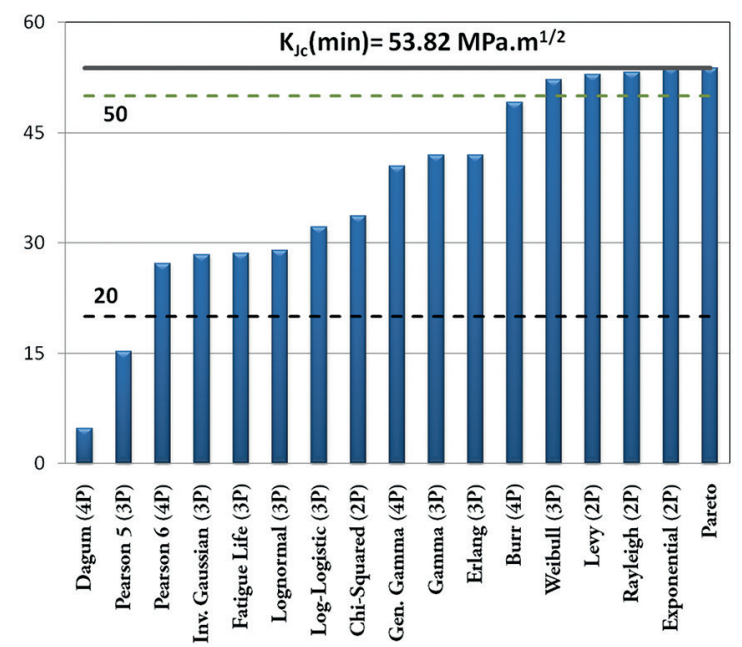

Figure 7: Threshold parameters for the adjusted distributions to the $\mathrm{K}_{\mathrm{Jc}}$ dataset. 
Special attention was paid to Rayleigh (2P) distribution (Eq. (5)). The scale and threshold parameters are $\mu$ and $\gamma$, respectively.

$$
P(\chi)=1-e^{-\frac{1}{2}\left(\frac{x-\gamma}{\sigma}\right)^{2}}
$$

The original Weibull distribution was presented by Weibull ${ }^{21}$, where he stated that the appropriate mathematical expression for a weakest link model has the form shown in Eq. (6)

$$
P(\chi)=1-e^{-n \varphi(x)}(6)
$$

In Eq. (6), $n$ is the number of links in the chain. Weibull also exposed that the simplest expression for the function $\varphi(x)$ is:

$$
\varphi(\chi)=\frac{\left(\chi-\chi_{u}\right)^{m}}{\chi_{0}}
$$

Equations (8) and (9) are two proposed distributions ${ }^{2,4}$, related to the weakest link model, but applied to fracture toughness characterization.

$$
\begin{gathered}
P(J)=1-e^{-\frac{B_{N}}{B_{1}}\left(\frac{J-J \min }{J_{0}-J_{\min }}\right)^{b}} \\
P(K)=1-e^{-\frac{B}{B_{0}}\left(\frac{K-K_{\min }}{K_{0}-K_{\min }}\right)^{b}}
\end{gathered}
$$

$\mathrm{B}_{\mathrm{N}} / \mathrm{B}_{1}$ and $\mathrm{B} / \mathrm{B}_{0}$ refer to a ratio size, being factors that take into account the probability of finding a different number of initiators cleavage sites in the crack tip. More initiators are found when this factors are greater than one, as the specimen size is greater.

The Rayleigh (2P) distribution presented in Eq. (5) can be considered as a particular case of the Weibull distribution, with $n$ equal to $1 / 2$ and the shape parameter equal to 2 , resulting:

$$
\varphi(x)=\left(\frac{\chi-\gamma}{\mu}\right)^{2}
$$

The advantage implicit in Eqs. (8) and (9) is their use for adjusting distributions for samples of specimens of different sizes. For instance, one may estimate the shape parameter for datasets of $\mathrm{B}_{1}$ or $\mathrm{B}_{0}$ sizes (Eq. (3)), and then using Eq. (8) or (9) the datasets of $\mathrm{B}$ or $\mathrm{B}_{\mathrm{N}}$ thicknesses would be adjusted. The factors $\mathrm{B}_{\mathrm{N}} / \mathrm{B}_{1}$ and $\mathrm{B} / \mathrm{B}_{0}$ would be the number $n$ of links in the chain presented by Weibull.

So, Eqs. (5), (8) and (9) are all mathematical expressions that respond to Weibull distribution. The main difference is that Eq. (5) considers as fixed the shape parameter, and no variation of size ratio is allowed, because it is fixed.

The statistical distribution imposed in ASTM E1921$15^{8}$ for the determination of the $\mathrm{T}_{0}$ reference temperature (Eq. (4)) is similar to Rayleigh distribution, in the sense that the shape parameter is fixed $(b=4)$, although it permits the variation of size ratio. This distribution is applicable to datasets of specimens of 1 ", no factor $\mathrm{B} / \mathrm{B}_{0}$ is included because the results for different sizes must be converted previously to 1 " thickness.

\section{Conclusions}

Jc values showed significant scatter for the AND420 steel at $20^{\circ} \mathrm{C}$ and $12.5 \mathrm{~mm}$ thickness. The three parameter Weibull distribution adjusted well to data on both Jc and $\mathrm{K}_{\mathrm{Jc}}$ parameters. This function presented a high threshold parameter compared to the other distributions analyzed.

The Rayleigh distribution presents a good adjustment for this sample. This function is a particular case of Weibull distribution (with shape parameter equal to 2). Further research must be performed in the direction of the convenience of Rayleigh distribution compared to the traditional Weibull function, using different samples sizes, and different materials.

\section{Acknowledgements}

To Consejo Nacional de Investigaciones Científicas y Tecnológicas (CONICET) and to Consejo de Investigación de la Universidad Nacional de Salta (CIUNSa) by the support to this work.

\section{References}

1. Landes JD, Shaffer DH. Statistical Characterization of Fracture in the Transition Region. ASTM STP 700. West Conshohocken: ASTM International; 1980. p. 368-382.

2. Landes JD, McCabe DE. The Effect of Section Size on the Transition Temperature of Structural Steels. West Conshohocken: ASTM International; 1984.

3. Wallin K. The scatter in $K_{I C-}$ results. Engineering Fracture Mechanics.1984;19(6):1085-1093.

4. Wallin K. Statistical aspects of constraint with emphasis on testing and analysis of laboratory specimens in the transition region. In: Hackett EM, Schwalbe KH, Dodds RH, eds. Constraint Effects in Fracture STP 1171. West Conshohocken: ASTM International; 1993. p. 264-288.

5. Heerens J, Hellmann D. Development of the Euro fracture toughness dataset. Engineering Fracture Mechanics. 2002;69(4):421-449.

6. Larrainzar C, Berejnoi C, Perez Ipiña JE. Comparison of 3P-Weibull parameters based on $J_{\mathrm{C}}$ and $K_{J \mathrm{C}}$ values. Fatigue \& Fracture of Engineering Materials \& Structures. 2010;34(6):408-422.

7. Perez Ipiña JE, Berejnoi C. Experimental Validation of the Relationship Between Parameters of 3P-Weibull Distributions Based in $\mathrm{J}_{\mathrm{c}}$ or $\mathrm{K}_{\mathrm{JC}}$. In: $13^{\text {th }}$ International Conference on Fracture; 2013 June 16-21; Beijing, China.

8. ASTM E1921-15ae1. Standard Test Method for Determination of Reference Temperature, To, for Ferritic Steels in the Transition Range. West Conshohocken: ASTM International; 2015. 
9. Iwadate T, Tanaka Y, Ono S, Watanabe J. An Analysis of ElasticPlastic Fracture Toughness Behavior for $J^{I c}$ Measurement in the Transition Region. West Conshohocken: ASTM International; 1983. p. 531-561.

10. Anderson TL, Stienstra D, Dodds RH. A Theoretical Framework for Addressing Fracture in the Ductile-Brittle Transition Region. West Conshohocken: ASTM International; 1994. p. 186-214.

11. Landes JD, Zerbst U, Heerens J, Petrovski B, Schwalbe KH. Single-Specimen Test Analysis to Determine Lower-Bound Toughness in the Transition. West Conshohocken: ASTM International; 1994. p. 171-185.

12. Heerens J, Zerbst U, Schwalbe KH. Strategy for Characterizing Fracture Toughness in the Ductile to Brittle Transition Regime. Fatigue \& Fracture of Engineering Materials \& Structures. 1993;16(11):1213-1230.

13. Heerens J, Pfuff M, Hellmann D, Zerbst U. The lower bound toughness procedure applied to the Euro fracture toughness dataset. Engineering Fracture Mechanics. 2002;69(4):483-495.

14. Neville DJ, Knott JF. Statistical distributions of toughness and fracture stress for homogeneous and inhomogeneous materials. Journal of The Mechanics and Physics of Solids. 1986;34(3):243-291.
15. Perez Ipiña JE, Centurion SMC, Asta EP. Minimum number of specimens to characterize fracture toughness in the ductileto-brittle transition region. Engineering Fracture Mechanics. 1994;47(3):457-463.

16. Wallin K. Fracture toughness of engineering materials - estimation and application. Warrington: EMAS publishing; 2011.

17. ASTM A615 / A615M - 15a. Standard Specification for Deformed and Plain Carbon-Steel Bars for Concrete Reinforcement. West Conshohocken: ASTM International; 2015.

18. ASTM E1820 - 13e1. Standard Test Method for Measurement of Fracture Toughness. West Conshohocken: ASTM International; 2013.

19. ASTM E1823 - 13. Standard Terminology Relating to Fatigue and Fracture Testing. West Conshohocken: ASTM International; 2013.

20. Mathwave. EasyFit - software. Available from: $<$ http://www. mathwave.com>. Access in: 18/02/2015.

21. Weibull W. A Statistical Distribution Function of Wide Applicability. Journal of Applied Mechanics. 1951;18(3):293-297. 